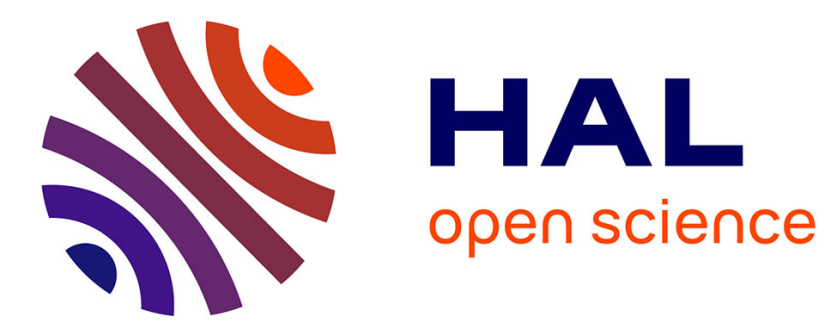

\title{
Muddled Boundaries of Digital Shrines
}

Nathalie Paton, Julien Figeac

\section{To cite this version:}

Nathalie Paton, Julien Figeac. Muddled Boundaries of Digital Shrines. Popular Communication, 2015, 13 (4), pp.251-271. 10.1080/15405702.2015.1019072 . halshs-01228530

\section{HAL Id: halshs-01228530 \\ https://shs.hal.science/halshs-01228530}

Submitted on 13 Nov 2015

HAL is a multi-disciplinary open access archive for the deposit and dissemination of scientific research documents, whether they are published or not. The documents may come from teaching and research institutions in France or abroad, or from public or private research centers.
L'archive ouverte pluridisciplinaire HAL, est destinée au dépôt et à la diffusion de documents scientifiques de niveau recherche, publiés ou non, émanant des établissements d'enseignement et de recherche français ou étrangers, des laboratoires publics ou privés. 


\title{
Muddled Boundaries of Digital Shrines
}

\author{
Nathalie Paton \\ Post-doctorate Research Fellow \\ LERASS - EA 827 \\ University of Toulouse \\ nathalie.paton(at)gmail.com
}

Julien Figeac

CNRS Researcher

LISST - UMR 5193

University of Toulouse

julien.figeac(at)univ-tlse2.fr

Popular Communication. The International Journal of Communication and Culture 2015, Volume 14, Issue 1. 


\begin{abstract}
:
Based on an online ethnography study of 274 YouTube videos posted during the Virginia Tech or the Newtown massacres, this article discusses how users resort to participatory media during such mediatized events to create a digital spontaneous shrine. The assemblage of this sanctuary on a website hosting billions of user-generated contents is made possible by means of folksonomy and website architecture, and a two-fold social dynamic based on participatory commitment and the institutionalization of a collective entity. Unlike "physical" spontaneous shrines erected in public spaces, these digital shrines connect the bereaved with provocative or outrageous contributions, notably tributes from school shooting fans using participatory media to commemorate the killer's memory. This side effect, generated by the technical properties of the platform, compromises the tranquility of the memorial and muddles the boundaries and the contents of such sanctuaries.
\end{abstract}

\title{
Key words:
}

Digital spontaneous shrine, commemoration, media ritual, participatory culture, media event, school shooting, public sphere, YouTube. 


\section{Digital spontaneous shrines in the wake of disruptive global media events}

\subsection{The continuum of commemorative practices online}

Burying the dead represents the ultimate rite of passage punctuating human life from "cradle to grave" (Van Gennep, 1977 [1909]). Just as this rite is practiced in various ways depending on the region of the world, the time period considered (Metcalf \& Huntington, 1979) and the social status of the deceased, associated commemorative rituals have developed in different manners over the years. One of the most significant commemorative rituals to take place nowadays is audiovisual media-based. These commemorations can take a televised form as “global media events" (Hepp \& Couldry, 2010), honoring great men and women selected to become a part of a historical pantheon. Large audiences followed for example the funeral of political leaders like Nelson Mandela or public figures like Lady Di, who were granted highprofile commemorations that rehashed their life story and accomplishments, within a matter of days after their death. While media events in general represent a driving force of social integration and thus form one of the strongest vectors of solidarity against the dispersion of individuals, these types of commemorative media events provide a sense of shared history and shape collective memory (Foote, 2003; Kammen, 1993). In these regards, acts of memorialization such as audiovisual media-based rituals are powerful tools at the hands of institutions - whether media, religious or state institutions - to design collective memory, shape beliefs, sway opinions and provide a sense of togetherness in relationship to a society. Yet memorial practices are not exclusively the by-product of top-down processes. Nowadays, "spontaneous shrines" regularly emerge "from below" (Misztal, 2003) on the site of a tragic event, in such a manner that people take power over how and what is to be commemorated. The aim of this article is to document the renewal of these bottom-up media-based commemorative practices and discuss some of their consequences. 
A handful of events, notably "bad deaths", i.e. the traumatic death of innocent people (Bradbury, 1993), can spark public outcry. These events lead to such overwhelming sorrow that the expression of grief and pain spills over into the public sphere instead of remaining confined to the privacy of one's home. This is typical of commemorative practices best known as "spontaneous shrines" (Kong, 1999; Hartig \& Dunn, 1998; Santino, 2006). These bottom-up commemorative practices, perpetuated as early as the 1980's and increasingly popular (Foote \& Grider, 2010), are materialized by objects - e.g. candles, flowers, stuffed animals, letters, etc. - deposited on the site where the death took place. Part of the cultural repertoire of emotional expressions of public mourning, such temporary assemblages allow people to create their own individual space of remembrance within the collective matrix of public mourning, leaving testimonies on the sanctuary site that would otherwise unlikely be publicized in the public arena. They therefore provide a way for people to weave the fabric of collective memories without calling upon an institution.

The development of participatory media contributes to this trend: the Internet users can nowadays publicly render a mediatized homage to the deceased. Family and friends of a loved one who has passed away compile pictures and mix them to music to produce a video or a slideshow presentation, for example. Such tributes, distributed within personal networks, are created and viewed via electronic means. This social practice, however, is not confined to personal social networks. By giving voice to people who seek to provide support to the families of victims of a social, political or climatic catastrophe, participatory media also allow bystanders and distant spectators to pay tribute on a larger scale, notably through "digital spontaneous shrines" (Grider, 2001; Santino, 2006). Digital shrines, also known as "virtual memorials" (Foote, 1999; Hebert, 2008; Mitchell et al., 2012), or "online deathscapes" (Maddrell, 2010), refer to temporary memorials people create via media participation, on a website, a blog or a wiki, for example (Hebert, 2008; Mitchell et al., 2012; Jakoby \& Simone, 
2013). By doing so, the Internet users transform the digital space into a site of remembrance and meaning and outline a place to grieve on the Web (Foote \& Grider, 2010). The private action of grieving is accessible to a worldwide audience, extending private practices far beyond the scale of the local community. This articles aims at observing how bystanders and distant spectators use participatory media resources to take part in the commemoration of violent deaths, and therefore how people take into their own hands the celebration of togetherness as well as the writing of their collective memories.

Scholarly work has mainly been carried out on virtual memorials confined to a specific page or website created for the sole purpose of commemorating the deceased. Therefore, it seemed appropriate to try to better understand a wider range of the variety of exchanges and commemorative practices that take place online in such instances. We chose YouTube for this purpose. YouTube is well-suited to investigate audiovisual media-based commemoration through online public participation in that it allows us to study how individuals can come together in the environment of a mainstream and hegemonic user-generated platform, not specifically designed to host large-scale social networks.

\subsection{Global disruptive events as a vector of participation: grieving online together?}

On April 16, 2007, Seung-Hui Cho a student at Virginia Tech University in Blacksburg, Virginia, U.S.A., slaughtered 32 people on campus before killing himself. Five years later, on December 14, 2012, Adam Lanza took the lives of 26 people at Sandy Hook Elementary School in Connecticut. Comparable to previous school shootings such as Columbine, these two episodes of extreme violence spiralled into highly publicized disruptive media events. Special news flashes interrupted regular TV programs in the United States, while making headlines worldwide, and heavy news coverage followed over several days. While each new 
case becomes a media event of strong intensity raising high levels of public concern, on such occasions, the local community constructs shrines on the site of the tragedy, as exemplified by the crosses erected in memory of Columbine victims near the high school (Spencer $\&$ Muschert, 2009). Due to the unthinkable nature of these tragedies and the resulting state of abandonment that can be felt by the TV viewers, rampage shootings can very well instill a need for togetherness and establish a feeling of belonging beyond the sight of the shooting. People can turn to the Internet during such events and unite from around the world, in order to share their grief, express their dismay and pay tribute through video homages. These disruptive media events indeed spark a participatory buzz on digital social networks prompting individuals to come together through online "cocoon communities" (Paton, 2013). School shootings, as a mass mediated phenomenon (Muschert \& Ragnedda, 2010) generating a high level of media participation, are therefore relevant to observe how participatory media enable commemorative practices in the wake of catastrophes. This contribution deals with a type of disruptive global media event commonly referred to as school shootings, i.e. premeditated shootings carried out by students on school grounds. It focuses on the Virginia Tech (VT) and Newtown massacres in particular, to illustrate the new forms of media commemoration with the development of participatory media.

If audiences nowadays take an active part in the hype surrounding media events and make use of the resources available to share information and communicate about current topics via the Internet, it is necessary to better understand the IT characteristics as well as the social dynamic involved. How does massive media participation lead to the formation of a shrine? How are the videos published on YouTube assembled? What binds and links people to the shrine? Through a case study of the Virginia Tech and the Newtown massacres, this article will detail how the aggregation of audiovisual productions forms a digital spontaneous shrine by means of specific sociotechnical resources. Three IT characteristics will be put forward: 
folksonomy, website architecture, and clustering. We will then show why it is necessary to take a closer look at the content of the material at hand to observe the formation of a digital shrine. The IT characteristics may provide a backbone to the digital network shaping the online shrine, however, this assemblage remains an open-end network of associations, links and individuals. In other terms, the network is infinite and not necessarily a shrine. For the assemblage of content to gain the status of a shrine, it is necessary for the participants to recognize their status as a group. It is only through the recognition of a collective entity and its' institutionalization through performed acts that a large network related to a digital shrine can take shape.

The online presence of sanctuaries enables people to reclaim power over the writing of collective memories and exemplifies new forms of social integration. However, the shrine's online presence also implies the lack of an institutional filter or publications without the laissez-passer of traditional gatekeepers of the public sphere, i.e. institutions. In these latter respects, studying digital shrines on a major website like YouTube is a way to investigate the effects of redefined public sphere boundaries with the development of participatory media. What happens when thousands of people come together to commemorate a high-profile mediatized catastrophe in one same place? Are the contributions homogenous? Do they aim at a same goal? Is the sacred ritual of commemorating the dead similar or altered when compared with its physical counterpart on the site of the tragedy? To reply, we will conduct in-depth analysis of the different formats of participation shared on YouTube and show how outsiders, mainly school-shooting fans, publish videos that take an opposing standpoint to the vast majority of participants. Their intention is to create dissension, if not to openly shock and engender conflict within the public debate on what causes this phenomenon. When folksonomy algorithms associate these ostensibly subversive contributions with other tributes, this aggregation produces an unfortunate situation for those whose only intention was to share 
their grief and temporarily set aside the news coverage of the event and its political realities. We will therefore consider how IT characteristics affect the permeability of the memorial site and in turn, discuss how commemorative contributions coexist with potentially opinionated, subversive or disruptive audiovisual montages, in such a manner that conflict and opposition muddle the boundaries of the shrine. The porous nature of the borders of a digital spontaneous shrine illustrates one of the consequences of an enlarged public sphere with the development of participatory culture.

\subsection{Method}

As specified earlier, our investigation of commemorative practices online will be based on the media participation in regards to the Virginia Tech (VT) and Newtown massacres on YouTube. Considering the wave of participation that followed these two disruptive media events, these high-profile school shootings are pertinent in examining how bystanders and distant spectators experienced the shootings. A snapshot of the level of media participation on this platform clearly illustrates this: to this day, more than 20,000 videos can still be found under the tag "Virginia Tech massacre" and over 36,000 recordings are associated with the tag "Sandy Hook massacre". The recording of the traffic on YouTube, via the integrated search engine, reveals the participatory hype generated by these media events within the first hours of the massacre: over 500 videos were posted on VT and roughly 1,200 videos published in relationship to Newtown within the same timeframe. Selecting a platform hosting thousands of both written and audiovisual messages paying tribute to the victims hence captures some of the main semiotic types of online expression possible.

We made our observations using an online ethnographic approach (Kozinets, 2010; Boellstorff et al., 2012), studying audiovisual discussions and their related discursive forums 
in their natural context, i.e. users' contributions. The Internet users' videos and profiles were viewed and analyzed. It seemed equally relevant to record the threads of their discussions in order to trace the exchanges they were weaving in a spontaneous but ephemeral manner. As tens of thousands of videos regarding the two shootings were uploaded onto YouTube, our analysis only focuses on the most representative among them. This study is composed of a corpus of 274 recordings posted by approximately 200 users.

\section{From a web of associations to the contours of digital shrines: the technical and social dynamics of spontaneous shrines}

When browsing through the huge number of commemorative videos related to the Virginia Tech or the Newtown massacres on a mainstream platform like YouTube, it is clearly apparent that bystanders and distant spectators took part in a tidal wave of participation. Thousands of videos, and just as many comments, were uploaded within the first few days. An outside observer may be under the impression that these contributions are nothing more than individual points of view. Yet, these audiovisual recordings shape a collective entity, specifically a spontaneous shrine. This article aims at providing insight as to how to a shrine takes shape within a website hosting billions of videos and why these videos merge into a virtual memorial rather than remaining disperse and separate contributions.

To do so, we will first focus on the referencing system of the website and the Web 2.0 participatory resource called folksonomy (Cattuto et al., 2007; Vander Wal, 2007). This will allow us to highlight how contents are associated and how the IT resources of the platform simultaneously form a web of semiotic associations and a vast social network. Virginia Tech will serve as a case study for this particular point. Then we will account for the ways in which the outlines of a shrine are established via social dynamics assembling the material at hand. If Internet users can exploit folksonomy to integrate their audiovisual recordings into a wider 
network of commemorations, this referencing system also creates an open-end network of associations, links and individuals. Unlike a website specifically dedicated to a shrine and in which a given border is embodied by the URL itself, the outline of a digital spontaneous shrine surfaces through shared commemorative dynamics. This social dynamic is two-fold: it translates into "participatory commitment" and the institutionalization of a collective entity. We will show this by analyzing the performative stances and material practices conveyed by the content of the videos published during the media events surrounding the Newtown or Virginia Tech shootings.

\subsection{Folksonomy and the aggregation of commemorations in a digital spontaneous shrine}

YouTube, as a participatory platform, is based on the principle of personal content indexing: YouTubers choose the categories, keywords and hashtags under which their videos will be referenced. To determine how the users named and referenced their video productions, we examined the various titles they were given. Due to its high incidence, contributors mainly classified their videos under the keyword "Virginia Tech". It designates and identifies the event under the name of the university where the shooting took place, using the classification made in news reports. This label is often associated with another one, that of "Massacre", which in turn describes the nature of the event. It is also coupled with other tags, such as "Tribute " or "Song", whose purpose is to identify the reason for the contribution.

Personal content indexing is used here by participants with only relative knowledge of the social classification procedures of folksonomy. Instead of pursuing an eminently strategic categorizing process focused on the optimization of queries to the search engine (Vander Wal, 2007), users most often tag their video to correlate their contributions to other videos that seemingly share the same motivations. The editorial work behind the processes of folksonomy 
nonetheless captures ongoing social dynamics and associates videos to one another, providing them with meaning within a similar universe of significations. Personal content indexing ultimately creates connection nodes in a vast web of associations and federates contributors sharing similar centers of interest in a same social network.

Although video referencing within YouTube is firstly based on the principle of personal indexing delegated to the user, the platform architecture and the algorithms behind its' general structure play a major role in putting forward specific material. This point is essential in understanding how a shrine can emerge on YouTube.

The platform collects the contents, prioritizes them and submits them to users via algorithms, the complexity of which will not be broached here. The user-generated classification system is tightly linked to YouTube's organization system, which prioritizes the recordings, earmarking them for curious visitors' attention. Consequently, any random observer can immediately identify the most popular subjects at a given time. In the case at hand, observations over the first six weeks following the tragedy show that this was especially true on April 16, 2007, when the participatory buzz linked to the massacre led to a high occurrence of tags associated with "Virginia Tech" on the FrontPage of the website. Moreover, the videos linked to this event were those "most viewed" on that particular day. Benefitting from worldwide exposure, the Virginia Tech school shooting became the "number one" subject on YouTube. By making FrontPage, these videos benefited from great publicity. This not only allowed media participation to become tangible, it also gave visibility to the formation of a social network related to a same topic. It should be noted that a shrine only exists while the event is highly publicized by the platform. The architecture, supporting prioritization of content, was therefore a key component in the structuring of the vast web of inter-textual references that allowed a shrine to emerge. 
If the mediatization of this particular school shooting immediately drew a large audience and triggered online participation, the videos did not instantly form a shrine. This marks an essential difference with traditional shrines where a bouquet is quickly placed on the site where the death occurred or a dedicated webpage is created to honor the memory of the deceased. The digital shrine occurs over time within YouTube; it develops in relationship to the number of contributions made by the Internet users and the amount of audiovisual or written material they publish. This does not mean to suggest that the digital shrine is the result of a long and timely process. Rather it highlights the fact that a cluster is required for a shrine to take shape. A cluster can only be achieved by numeric accumulation and thus by means of a dynamic process within a given bracket of time, whether it be over a few days, weeks or months, or only a matter of minutes. To illustrate the configuration of this shrine over time, it is relevant to represent the number of videos broadcast on YouTube that were tagged by users as referring to the "Virginia Tech" school shooting (Figure 1).

Figure 1. Number of published videos linked to the VT massacre

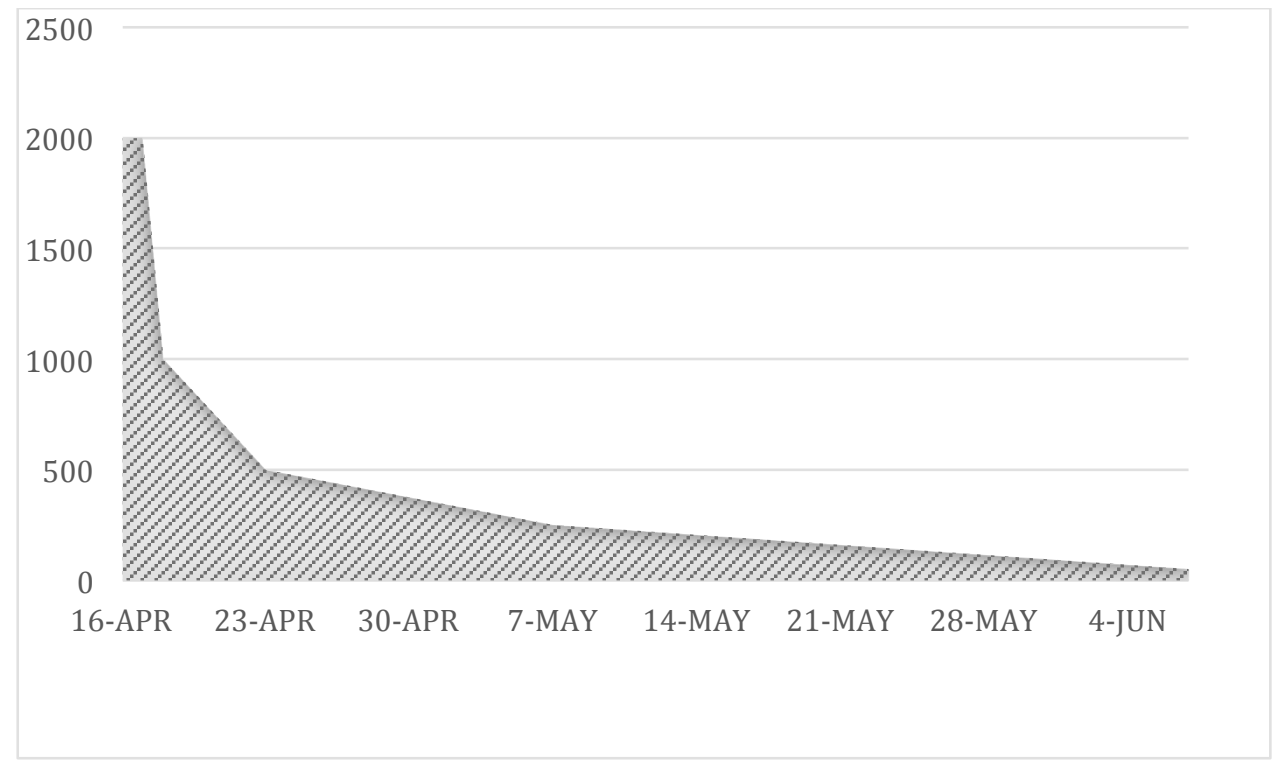


Even if this graph is not exhaustive, it gives a good estimation of the number of contributions published after the facts. On the day of the school shooting, it appears that approximately 2,000 videos were broadcast. With 3,000 additional videos published over the next two days, the participatory buzz was sufficiently tangible during the first three days for an online spontaneous shrine to emerge. The participation rate remained high for about another month as participants published approximately 200 videos per day one month after the shooting. However, two months after the massacre, publication slowed down significantly to around 50 videos uploaded per day. Even if this shrine was progressively abandoned from then on, the material itself has not disappeared and the audiovisual productions are still online seven years later. As mentioned earlier, more than 20,000 videos can still be found under the tag "Virginia Tech massacre" on YouTube. However, content prioritization as designed on YouTube is what maintains the shrine; otherwise, only the material that composed it would still exist, not the sanctuary itself. The material left behind is simply a trace of the contributors' intent.

\subsection{The audiovisual tribute as a mode of participatory commitment}

Now that we have demonstrated the ways in which sociotechnical dynamics create the backbone of the digital shrine, we shall consider how the outline of the sanctuary is determined by a two-fold social dynamic. The first dynamic corresponds to "participatory commitment".

A closer look at participants' remarks allows us to observe that YouTube is an outlet for strong and troubled collective emotion, characteristic of a spontaneous shrine. As one contributor puts it, producing a video conveys what words cannot express:

A tribute to all of those lost at VT I didn't know what to say because I'm speechless so I thought I would make this tribute to let it say what words just cannot manage. ${ }^{1}$

\footnotetext{
${ }^{1}$ http://www.youtube.com/watch?v=m2ZafFtg5IM
} 
Media participation here is directed towards sharing personal suffering, related to the victims' status as innocent people who died for no reason:

This made me cry so bad (ndr watching the video) they died before their lovely holidays 20 children lost their lives im (sic) so sorry to those innocent children and their families will always have their children in their heart god im begging you to bless sandy hook victims and childtens (sic) famles (sic) R.I.P innocent children. ${ }^{2}$

I don't understand why they would do something like this. It seems really senseless and it's really hard to think about why all these people had to die for no reason ${ }^{3}$

While contributors evoke the fact that they feel helpless when discovering the violence of Seung-Hui Cho's or Adam Lanza's crime, they also feel a compulsion to react, to become involved. They have found no better way to do so than to produce and publish a video:

I don't know what this video will ultimately accomplish, I began putting it together to help me cope, and I suppose I wanted it to give some semblance of comfort and hope to families of the Newtown, Connecticut shootings on 12/14/12. (...) I sincerely hope this video helps in your grieving process for this awful tragedy. ${ }^{4}$

When I heard the news about the tragedy in Newtown my heart broke. I have always loved young children so much. I saw that there were requests for prayers, and some families needed some financial support to help get them through. Because I'm just 13 I don't have any money, so instead I decided to write a song, which helps me process everything I go through. Hopefully, it can help others as well. ${ }^{5}$

Self-produced videos are thus a vector allowing contributors to take action. They want to participate in this digital shrine to bring comfort and support to the victims, their families and

\footnotetext{
${ }^{2} \mathrm{http}: / / \mathrm{www}$. youtube.com/watch? $\mathrm{v}=\mathrm{dCKK} 2 \mathrm{spGRFU}$

3 http://www.youtube.com/watch?v=35gbUVxoF10

4 http://www.youtube.com/watch?v=1xlCGTOaNUU

5 http://www.youtube.com/watch?v=0UmQDkzanSk
} 
more generally, to the mass of anonymous people online who, like them, feel pain due to this tragedy:

My intent for this video was to capture how people can come together in time of tragedy and hopefully bring some comfort to those who are suffering through such a horrific loss of loved ones lost in this tragedy ${ }^{6}$

Thanks to a few lines such as the ones above, YouTubers express how they would like to get involved by adding their contributions to the ones already published. The videos also share the same emotion and tonality, allowing users to shed their feelings of helplessness by taking action.

Contributors' audiovisual tributes are forms of "participatory commitment" undertaken in reaction to the tragedy and the emotion felt at a distance. As one of the Internet users puts it, his video is meant to "heal the pain"7; through his tribute, he is committed to alleviating suffering of the local community and bystanders. This specific shared dynamic is characteristic of spontaneous shrines in which people react to bad deaths by becoming involved with the community formed. In this respect, participatory commitment tends to tighten the interweaving of the digital contributions.

\subsection{Institutionalization of a collective entity}

The second level of the two-fold social dynamic corresponds to the institutionalization of a collective entity. Within the self-produced videos, the use of text, sound and visual signs shows a sort of attachment. Participants recycle various sayings in reference to the Sandy Hook elementary school such as " 26 angels"8 (i.e. the number of people killed by the

\footnotetext{
${ }^{6}$ http://www.youtube.com/watch? $\mathrm{v}=5 \mathrm{~J} 0 \mathrm{Kcddcx} 1 \mathrm{Q} \&$ feature $=$ related

7 http:/ / www.youtube.com/watch?v=ZsTZfaY9Fs\&feature= related

${ }^{8}$ https://www.youtube.com/watch?v=42MN315IasU
} 
massacre), certain slogans such as "We are Newtown", and songs composed expressly in commemoration of the massacre (for example We'll Be Alright-Newton CT Tribute ${ }^{10}$ or Heaven Got Another Angel11). Each of these attachments materialises the fact of belonging to a community. Even more than attachment, media participation guarantees the existence of an imagined community, through enunciation of formulas such as: "we mourn with you Newtown"12, "our hearts are with you all through this devastating time"13 or "we will stand with you, we are yours and you are ours as brothers and sisters in this great (...) human family"14. Through the proclamation of these imagined communities, a collective entity takes shape and is defined.

This collective aspect is not simply produced through these performative acts of language and material practices; the Internet users follow through with a form of self-recognition. One of the videos from our sampling shapes a collective entity by regrouping different emblems of solidarity posted on YouTube. This video is not addressed so much to victims as to the audience. As the creator puts it:

The outpouring of Love \& Support for the victims of the Sandy Hook School shooting was unbelievable. Newtown received comfort from all over the world. I felt the need to document these acts of kindness (...). We are Newtown. We are Strong. ${ }^{15}$

It is thus intended to reflect the support shown to this elementary school.

The enunciation, materialisation, as well as self-recognition practices of the sampling converge towards a common narrative, whose terms aim at demonstrating unity. For the assemblage of content to become a digital shrine, it is necessary for the participants to

\footnotetext{
${ }^{9}$ https://www.youtube.com/watch?v=lvPOyKgK8MQ\&list=PL4asalZIHZxMR6il5YIol-bkrHXXCITTF https://www.youtube.com/watch?v=f70biOcMvuE

10 https://www.youtube.com/watch?v=oTNjTNoG-1A

11 https://www.youtube.com/watch?v=1Jojv6CZgn8

12 https://www.youtube.com/watch?v=osWWnu5qcRc

13 https://www.youtube.com/watch?v=9gdGp8ITIA8

14 https://www.youtube.com/watch? $\mathrm{v}=3 \mathrm{JhYKCZi}-\mathrm{dA}$

15 https://www.youtube.com/watch?v=_MWTcg-Lbp4
} 
recognize their status as a group. These performances thus bond the gathering together into a single entity while outlining the sanctuary borders. It is only through the recognition of a collective entity and its' institutionalization through performed acts that a large network can take shape to harbor a digital shrine. This tends to seal the potentially open-end network of individuals, associations and links in a more impermeable manner than mere technical properties do.

\section{Gathering in remembrance within a digital spontaneous shrine vs. the serendipity of}

\section{folksonomy}

The previous sections have shown how thousands of online contributors use participatory media in reaction to certain global media events in an attempt to bring mediatized support. By describing the steps leading to the formation of digital shrines in the wake of high-profile school shootings, we have stressed two concomitant dynamics interplaying to shape such entities: a social dynamic linked to a desire to honor the victims' memory and a particular emotional tonality, characteristic of any participation in spontaneous shrines, entwined with the more technical characteristics of the participatory platform and its' architecture.

As soon as we focus on the contents of the videos and sort them into distinct categories according to their respective narrative structures, various trends materialize in the participatory wave triggered by the school shootings. First, there is subversive participation. This includes videos published by school shooters before they carry out the shooting, in an attempt to pre-mediatize the event and prepare their future fame. Subversive participation also comes in the form of video recordings and comments provided by fans of this sort of extreme violence, who actively publish each time a school shooting takes place. They do so in order to celebrate the radical act and commemorate those responsible for this form of violence (Paton, 2012). Then there are those who upload the vast majority of videos associated with school 
shootings, i.e. the general public. In this latter category, there are those who produce remixes based on images from special news flashes to relay information they deem to be pertinent. There are also those who, facing a camera, film themselves to express indignation and/or attempt to explain this phenomenon and suggest possible solutions. Finally, there are those who are at the very core of the memorialization process, publishing what they call "tributes". Not only are these people responsible for the social dynamics transcending the sanctuary, they also produce the greatest number of videos. Representing $63 \%$ of the material collected for this study, they are, quantitatively speaking, the most important component of a sanctuary. While ultimately all these contributions co-exist, the assemblage of different genres muddles the boundaries of the very shrine that the vast majority of contributors have erected. By examining the contents of the videos and the significations they convey, not only will we show how these genres emerge with respect to one another, we shall also demonstrate the importance of going above and beyond simply analyzing the sociotechnical properties of shrines. Only in this manner is it possible to fully comprehend how the boundaries of spontaneous shrines are significantly affected and thus muddled by opposition and conflict. We will demonstrate this by analyzing the different video genres in reverse order of their presentation hereabove.

\subsection{Tributes via audiovisual remixes and musical performances}

The social dynamic mentioned on several occasions is connected to a format of participation in which contributors pay tribute to the victims and their families to commemorate the "bad death". Two types of audiovisual commemorations can be distinguished: productions based on a remix of the victims' pictures and musical performances.

In the first case, distant spectators produce audiovisual remixes honoring the victims. Users take extracts from news programs and victims' portraits published online. These media 
contents are reworked in a spirit of the remix poietic in that contributors cut them up, reorganize them and rework the sound track. The video published by "deepkholi" illustrates this tendency ${ }^{16}$. In the introduction, deepkholi wrote the following dedication on a black background:

This video is dedicated to the victims as well as everyone who is affected by the April 16, 2007 shootings on Virginia Tech Campus. Stay strong, VT. The nation is right behind you.

Like other contributors to the shrine, he dedicates his memorial to the local Virginia Tech community, to the victims and their loved ones, to the university students and academic staff. After the introduction, he inserts a logo representing a black, knotted ribbon on which the university initials are printed in red letters (Image 1). Under this logo, he states: "Today, everyone is a "hokie" (a "hokie" being a member of one of the university sports teams). The fact that he places the expression "Heal the pain" under the logo categorizes the tonality of his committed participation: he thus renders homage to the members of this community to help "heal the wounds" and alleviate the pain felt.

Following this, his tribute is organized around a narrative woven by associating several facets of the shooting: 1. Portraits of the 33 shot and killed during the shooting are posted in batches of 6 (Image 2); 2. Pictures of representatives of law and order and rescuers in action are inserted to depict the crisis taking place (Image 3); 3. Emotion aroused by the massacre is visualized through photos of the local community in mourning (Image 4); 4. The spontaneous shrines erected at VT are illustrated (Images 5,6). The emotion in this video is scripted and enhanced by background music, in this case Adiemus interpreted by Enya.

\footnotetext{
${ }^{16}$ http://www.youtube.com/watch?v=_ZsTZfaY9Fs\&feature=related
} 

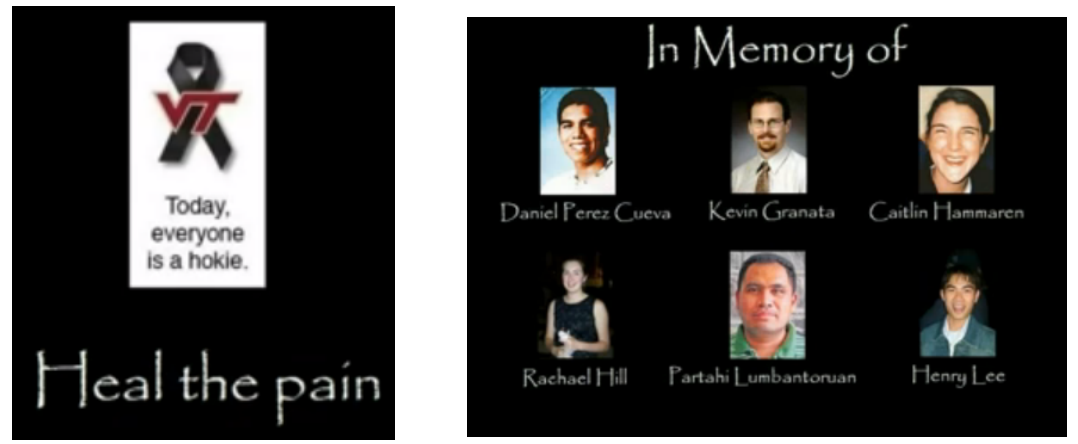

Image 3

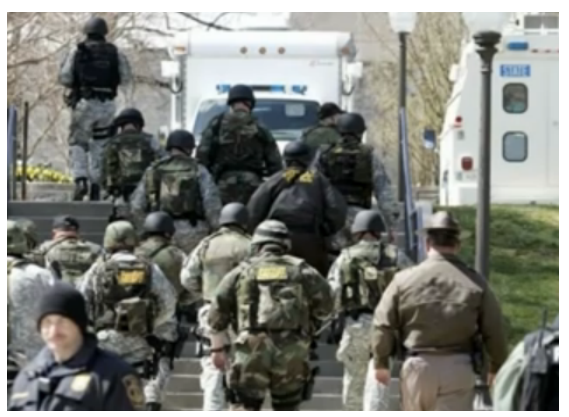

Image 5

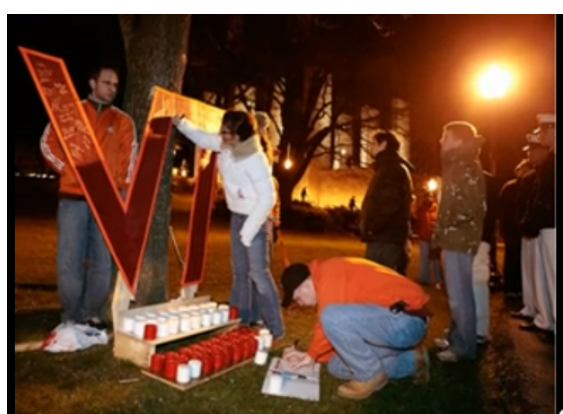

Image 4

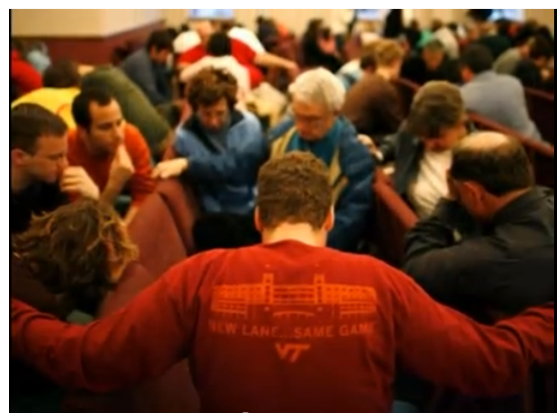

Image 6

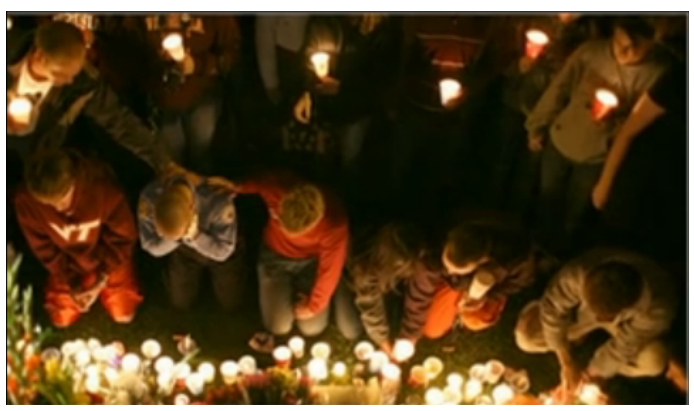

Certain videos attempt to pay a more personalized tribute to the victims rather than letting them be permanently reduced to some random media list. The video entitled "Newtown 
Tribute"17 illustrates this: a quick description of the victim displayed on the bottom left-hand side of the screen is associated with a picture of him/her (Image 7).

\section{Image 7}

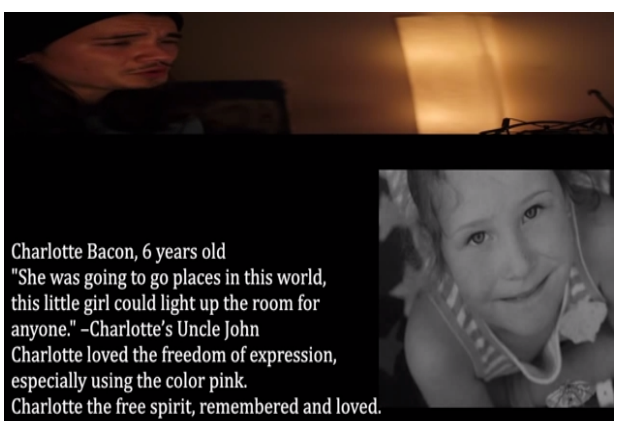

In the second case, contributors delivered their homage in the form of a musical performance.

The Internet users compose songs inspired by the school shooting before recording them as the sound track for their audiovisual remixes ${ }^{18}$. They dedicate them to the victims, in an attempt to show compassion for them and support for their loved ones:

As a tribute to the lives lost in the Sandy Hook School shooting in Connecticut, I felt led to write this song. I pray that this song will bring peace and comfort to the hurting families. ${ }^{19}$

Most of the time, these self-produced musical tributes are modeled as "vlogs": the amateur composers/performers use a webcam to film their performances, either facing the camera (Image $8^{20}$ ) or showing their profile (Image $9^{21}$ ).

\section{Image 8}

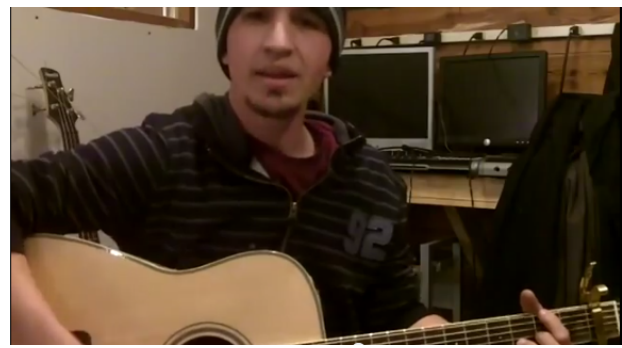

Image 9

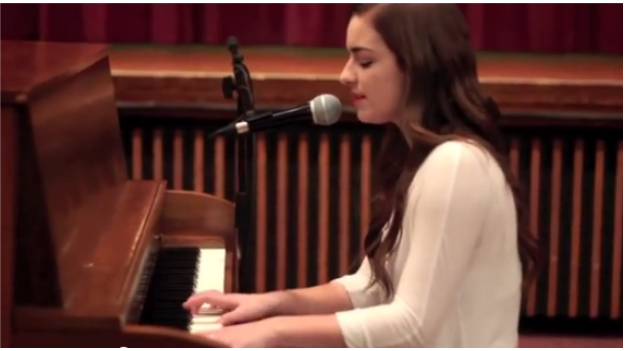

\footnotetext{
17 http://www.youtube.com/watch?v=hZRRvYtM940

18 http://www.youtube.com/watch?v=HyFXvSArOuw

${ }^{19} \mathrm{http}: / /$ www.youtube.com/watch? $\mathrm{v}=\mathrm{u}-8 \mathrm{Wc} 2 \mathrm{GImDY}$

${ }^{20}$ http://www.youtube.com/watch?v=hlSpxaL01NA

${ }^{21}$ http://www.youtube.com/watch?v=J31XishbcQc
} 
Since the VT massacre, contributors have increasingly chosen to pay musical tributes and engage in more collective musical performances. Videos show bands (e.g. Image 1022) or choirs as they sing (e.g. Image $11^{23}$ and Image 1224).

Image 10

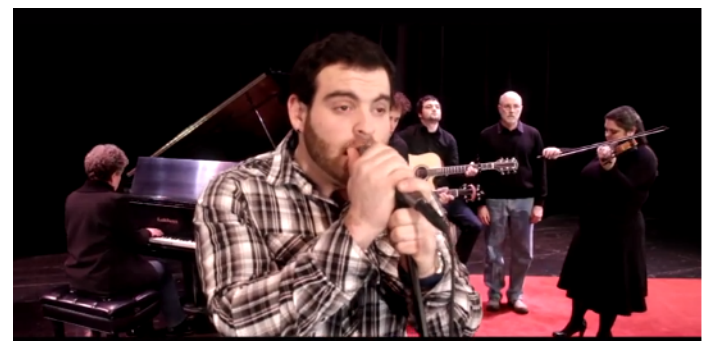

Image 11

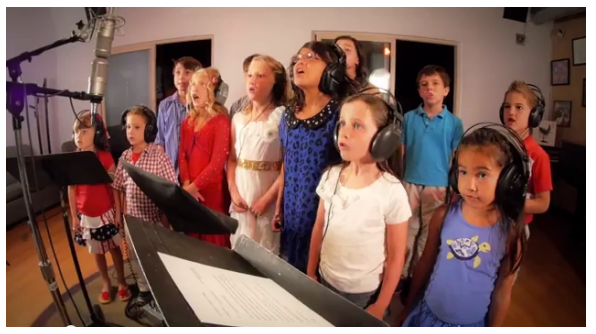

Image 12

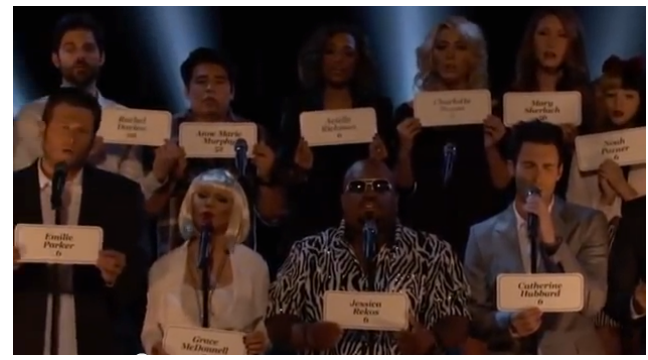

Despite differences in the ways singers take center stage, these commemorations reflect the same desire to render homage and converge to transform the commemorated school shooting into a tragedy extending beyond the local scale.

\subsection{Vlogging as a "committed" means of expression}

Among the various sorts of videos published on YouTube linked to the Virginia Tech or Newtown "school shooting" tag, it is possible to find videos in which users express their opinions and suggest solutions to eradicate school shootings. These videos represent $15 \%$ of the sampling. In order to focus on the main characteristics of digital shrines in settings like

\footnotetext{
${ }^{22}$ http://www.youtube.com/watch?v=nATJ1vrhgT8

$23 \mathrm{http}: / /$ www.youtube.com/watch? $\mathrm{v}=\mathrm{sMvAJmgXV} 2 \mathrm{w}$

${ }^{24}$ http://www.youtube.com/watch?v=c1JvtStvoYw
} 
YouTube, this article has only vaguely referred to this latter kind of video, even though they are commonly found. Those who want to publicize their analyses film themselves in "video blog" ("vlogging") tradition. Via vlogging, contributors address the camera, framing the shot around the upper part of their body in the manner of a headshot (Image 13), and reply to one another in a similar manner. In the present case, the décor has not been fine-tuned; the filming takes place at home or at a workplace. No effort has been made to make the backdrop more presentable than it normally is. Contrarily to musical performances, corporal expression is minimal. The purpose behind this configuration is to publicly express a personal analysis delivered in the form of a monologue.

Image 13

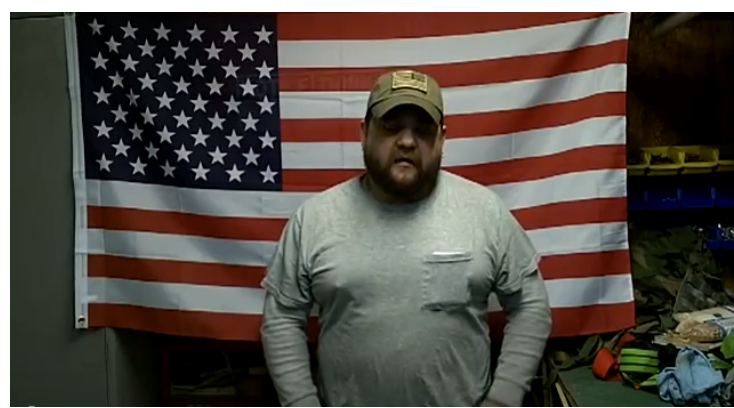

AA (sic) tragedy took place on 12-14-2012. 20 children and 8 adults were killed by a lone gunman. I touch on the knee jerk reaction for gun control that may occur. My condolences to the victims families. ${ }^{25}$

Contrasting with publications rendering homage to the victims of the Newtown massacre, the user posting the comments above expresses his indignation in order to kindle a debate on the origin of the shooting, and consequently, on the remedial measures that need to be implemented as well as one that would be useless in his opinion, that is, more gun control. Throughout this type of monologue, the Internet users unravel their interpretations, echoing

\footnotetext{
${ }^{25}$ http://www.youtube.com/watch?v=d0COkZ_KLPM
} 
those proposed by the press, reply to one another and defend their personal opinions regarding a particular stance or solution.

These messages reflect conflicting explanations for Cho and Lanza's violent crimes. More importantly, they stand out from the profound sadness and incomprehension conveyed by participation in a spontaneous shrine. Even if this type of video may be punctuated by messages of support, the contributors' purpose is to take part in the public debate on the causes of school shootings, trying not only to advance their opinions and explanations for the phenomenon but also to eradicate it. Commemorative remixes, on the other hand, attempt to put aside the conflicting issues to cope with the emotional shock felt following the massacre.

\subsection{Digital spontaneous shrines tagged by school shooting fans}

As the last example implies, folksonomy algorithms are not always conducive to serendipity. School shooting fans provide another example. They keep an underground subculture alive in participatory platforms by sharing subversive videos and republishing on the Web those that were censored (Paton, 2012). Each new school shooting gives them an opportunity to honor the memory of past school shooters and expose their views to a large audience. They do so by broadcasting, particularly on YouTube, audiovisual montages in memory of those who "rest in peace" in the pantheon of this subculture, i.e. the shooters, thanks to the fame they have acquired in carrying out a school shooting. This subversive format of participation must be briefly described to understand how these contributions interplay with their counterparts.

On the sidelines of the participatory hype created by school shootings, it is possible to find fans of this phenomenon. They speak up to suggest counter-interpretations that legitimize the school shooting. They defend the thesis that this recourse to violence is a necessary evil. These contributors, who are used to seeing their publications censored, know how to draw the 
attention of those honoring the victims' memory to their subversive position. Most often, they slip in comments such as "the shooter is a hero", "Cho $<3$ " or "R.I.P. Lanza" under the videos of other contributors. Others produce videos themselves and force their way into the public debate. While this kind of video corresponds to approximately $5 \%$ of the sample, provocative comments are far more prevalent than opposing videos. Hereafter, an example portrays this kind of mediatized participation. It embodies the idea that these contributors ostensibly seek to interfere with the tribute paid to the victims in a digital spontaneous shrine by mimicking and distorting the format of hegemonic "tributes" to create a counter-format. In this manner, fans can oppose the general consensus that such massacres are a tragedy.

In the selected example, the fan posted his video three days after the VT shooting. He labels it "A different type of Tribute" to contrast with the titles of the multitude of homages rendered to the VT shooting victims. He stipulates that the video is dedicated to the real victim of the shooting and invites others to react: "This is a tribute to the real victim of VT. Please feel free to rate and share comments". His understanding of the law is that he can protect himself from the possibility that his video will be censored by evoking the First Amendment of the U.S. Constitution: "I post this under the rights granted to me under the 1st Amendment". That having been said, he states that YouTube moderators (Image 14) should not censor his video since they allow numerous other so-called violent recordings to remain in circulation, for example, that of Saddam Hussein's hanging, which took place shortly before. Following this introductory phase, he starts his remix by using photographic self-portraits and video recordings broadcast by Seung-Hui Cho before he went on a killing spree. This fan adds a Heavy Metal soundtrack, using the song Bodies by the group Drowning Pool. In it, the refrain, "Let the Bodies Hit the Floor" is chanted, while the group counts from one to four. This contributor appropriates this enumeration to compose a musical backdrop against which the portraits of the victims are exhibited, just like in the audiovisual homages usually 
rendered. In this instance though, the victims are splotched with red spots representing the impact of bullets. This fan thus perpetuates a technique used by contributors to this digital subculture linked to school shootings by rendering homage to the "real victims", that is, those named at the beginning of the video, or to use the killer's own words, "the weak and defenseless." The fan proclaims that the act is a necessary evil and invites the Internet users to let an invisible revolution take place (Image 15). It is a revolution that youth from several continents have called for ever since the perpetrators of the Columbine massacre promulgated it in 1999 with the formula "Let's kick-start a revolution."

Image 14

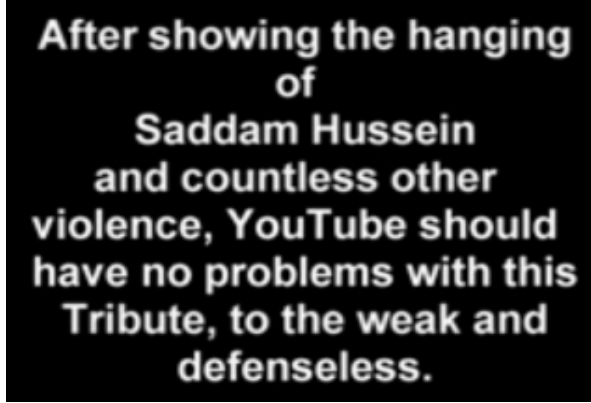

Image 15

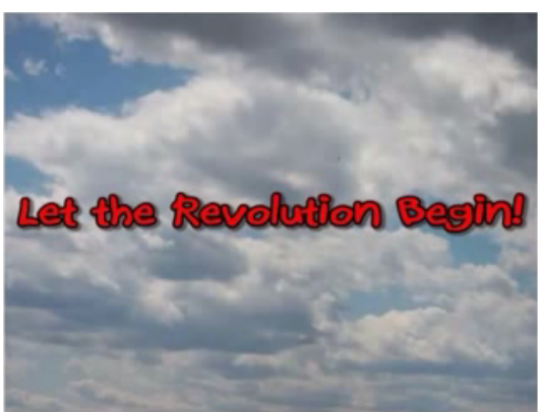

This example shows how media arenas like YouTube are unable to allow users to demonstrate mourning in audiovisual or written homages to victims unless they allow their coexistence with more radical positions, even messages ostensibly conveying a counter-interpretation, in defiance of the collective emotion channeled by the media. That does not keep a number of actors from trying to regain control over the gathering and the collective memories weaved together in these instances. The platform algorithms are precisely designed to censor any content promoting violence. Mourning online contributors' are also fast in denouncing, via the robotized flagging system of the platform, fans' publications. Although these newfound gatekeepers of the public sphere regain some degree of control in such ways, conflictuality cannot be silenced. It is an integral part of this type of digital shrine, muddling the boundaries of what is meant to be a gathering conducive to mourning. 


\section{Conclusion}

This article shows how distant spectators and bystanders use participatory media parallel to the news coverage of global disruptive media events, in this instance school shootings, in order to pay an online tribute to the victims' memory. Digital commemorations are discussed on two levels of analysis in particular.

Firstly, this article identifies how the formation and the outline of a digital shrine are coproduced by IT characteristics and social dynamics. By stressing the main sociotechnical dynamics at work behind such digital shrines, we have demonstrated that the clustering of videos are bound together into a vast network of semiotic links by the means of folksonomy properties and the architecture of the website. We have also revealed a two-fold social dynamic. If Internet users build the ground floor for commemoration and gathering on a global scale via IT characteristics, they also cement their gathering through participatory commitment and institutionalization of a collective entity. Internet users come out of isolation, overcome the fact they are dispersed and gather together in remembrance on the Web. Simultaneously, they acknowledge the importance of seizing this type of media event to reaffirm their sense of belonging to and constituting a society.

Secondly, by differentiating the narrative structures of the main video formats used, this article analyzes and considers how the sociotechnical properties of digital shrines can tarnish serendipity. While the main thread of publication relates to commemorative practices, thousands of videos are also self-produced with the intention of kindling the public debate on what causes this phenomenon and how to frame the killers. Certain even publish videos to honor the memory of the school shooters, whom they generally consider to be the real victims of everyday violence, of school bullying. These audiovisual productions, indignant or ostensibly subversive, are so numerous that folksonomy algorithms place them with the audiovisual tributes. This aggregation produces an unfortunate situation in the eyes of those 
whose only intention, in connecting to the participatory site, was to share their grief and temporarily set aside the news coverage of the event and its political realities.

It appears that the borders of a digital spontaneous shrine are infinitely porous. These digital forms never allow sounds of contention to be muted in order to dedicate a minute of silence to the memory of the victims. If the accumulation of contributions tries to mark the boundaries of a participatory space dedicated to remembrance, it seems that this territory cannot be separated from political realities. This particularity differentiates them from "physical" spontaneous shrines in that the latter offer the possibility of temporarily putting aside dissension, even if this temporary break is sometimes enforced by the police and various means available to physically circumscribe the pictures, flowers, candles and inscriptions that make up a spontaneous shrine. Discussing the muddled boundaries of digital shrines therefore allows us to examine some of the consequences of participatory culture, notably how the public display of private emotions is renewed by the emergence of new media arenas, how the redefinition of the place and role of gatekeepers affects collective rituals.

\section{References}

Boellstorff, T., Nardi, B., Pearce, C., \& Taylor, T.L. (2012). Ethnography and Virtual Worlds: A Handbook of Method. Princeton: Princeton University Press.

Bradbury, M. (1993). The “Good” Death?”. In Dickenson, D. \& Johnson M. Death, Dying and Bereavement (pp. 59-63). London: Sage.

Cattuto C., Schmitz C., Baldassaria A., Vito, D.P., Loreto, V., Hotho, A., Grahl, M., \& Stumme, G. (2007). Network Properties of Folksonomies. Ai Communications, 20 (4), 245262. 
Foote, K. E. (1999). Virtual Memorials. In R. Gottesman, \& R., Brown (eds.) Violence in America: An Encyclopedia (pp. 356). New York: Scribner's.

Foote, K. E. (2003). Shadowed Ground: America's Landscapes of Violence and Tragedy. Austin, TX: University of Texas Press.

Foote, K. E., \& Grider, S. (2010). Memorialization of US College and University Tragedies: Spaces of Mourning and Remembrance. In A. Maddrell \& J.D. Sidaway, Deathscapes: Spaces for Death, Dying, Mourning and Remembrance (pp. 181-205). Farnham, UK: Ashgate.

Grider, S. (2001). Spontaneous Shrines: A Modern Response to Tragedy and Disaster. New Directions on Folklore, 5 (October). http://astro.temple.edu/ camille/shrines.html

Hallam, E., \& Hockey, J. (2001). Death, Memory and Material Culture, Oxford: Berg.

Hartig, K.V., \& Dunn, K.M. (1998). Roadside Memorials: Interpreting New Deathscapes in Newcastle, New South Wales. Australian Geographical Studies, (36), 5-20.

Hepp, A., \& Couldry, N. (2010). Introduction: Media Events in Globalized Media Cultures. In N., Couldry, A., Hepp, \& F., Krotz (Eds.) Media events in a global age (pp. 1-20). London: Routledge.

Jakoby, N. R., \& Simone, R. (2013). Grief 2.0. Exploring Virtual Cemeteries. In T., Benski, \& E., Fisher (Eds.) Emotions and the Internet (pp. 65-79). London: Routledge.

Kammen, M. (1993). Mystic Chords of Memory: The Transformation of Tradition in American Culture. New York: Vintage.

Kozinets, R.V. (2010). Netnography: Doing Ethnographic Research Online. Sage: London. 
Kong, L. (1999). Cemeteries and Columbaria, Memorials and Mausoleums: Narrative and Interpretation in the Study of Deathscapes in Geography. Australian Geographical Studies, $37,1-10$.

Maddrell, A, (2010). Memory, mourning and landscape in the Scottish mountains: discourses of wilderness, gender and entitlement in online and media debates on mountainside memorials. In E., Anderson, A. Maddrell, K. Mclouglin,\& E. Vincent (Eds.) Memory, Mourning and Landscape. Amsterdam: Rodopi.

Metcalf, P., \& Huntington, R. (1979). Celebrations of Death: The Anthropology of Mortuary Rituals. Cambridge University Press.

Misztal, B. A. (2003). Durkheim on Collective Memory. Journal of Classical Sociology, 3.2, 123-143.

Muschert, G.W., \& Ragnedda, M. (2010). Media and Violence Control: The Framing of School Shootings. In W., Heitmeyer, H.G., Haupt, S., Malthaner, \& A., Kirschner (Eds.), The Control of Violence in Modern Society: Multidisciplinary Perspectives, From School Shootings to Ethnic Violence (pp. 345-361). New York: Springer Publishing.

Paton, N. (2012). Media Participation of School Shooters and Their Fans. Navigating Between Self-distinction and Imitation to Achieve Individuation. In G.W, Muschert \& J., Sumiala (eds.), School Shootings: Mediatized Violence in a Global Age (pp. 203-229). UK: Emerald.

Paton, N. (2013). Virginia Tech Massacre: When a Disruptive Media Event Triggers an Online Cocoon Community. In M., Korpela \& F., Derwin (eds.), Cocoon Communities: Togetherness in the 21st Century (pp. 81-104). Cambridge Scholars Publishing.

Rosenblatt, P., Patricia C., Walsh, R., \& Jackson, D.A. (1976). Grief and Mourning in Crosscultural Perspective. New York: Human Relations Area Files Press. 
Santino, J. (2006). Performative Commemoratives: Spontaneous Shrines and the Public Memorialization of Death. In J., Santino (Ed.) Spontaneous Shrines and the Public Memorialization of Death (pp. 5-15), New York: Palgrave MacMillan.

Spencer, J. W., \& G.W., Muschert (2009). The Contested Meaning of the Crosses at Columbine. American Behavioral Scientist, 52 (10), 1371-1386.

Van Gennep, A. (1977 [1909]). The rites of passage. Routledge: London.

Vander Wal, T. (2007), Folksonomy Coinage and Definition,

http://vanderwal.net/folksonomy.html 